\title{
Curriculum-Focused Design
}

\author{
Jennifer A. Rode ${ }^{1}$, Mark Stringer ${ }^{1}$, Eleanor F. Toye ${ }^{1}$, Amanda R. Simpson ${ }^{2}$ \& Alan F. Blackwell ${ }^{1}$ \\ ${ }^{1}$ Computer Laboratory \\ University of Cambridge \\ Cambridge CB3 0FD, UK \\ $+44(0) 1223763500$ \\ \{jar46, ms508, eft20, afb21\}@cl.cam.ac.uk
${ }^{2}$ CeNTRE, Institute of Education
University of Warwick
Coventry CV4 7AL UK \\ +44 (0)24 76523855 \\ A.R.Simpson@warwick.ac.uk
}

\begin{abstract}
In this paper we describe a technique of CurriculumFocused Design, and the aspects of our research experience on which the technique is based. Our technique is a variant of Druin's Cooperative Inquiry. Cooperative Inquiry is a well-developed design practice for children, but it has been practised largely outside the classroom. Druin's technique has also been developed in American schools, which have greater curriculum flexibility than English schools, which are highly curriculum-focused. We studied the English curriculum and identified an area that we believed could fruitfully be augmented by technology. Our design approach was novel insofar as our evaluation sessions doubled as lessons for students. Our interdisciplinary design team, including a former teacher with over 10 years' classroom experience, evaluated the interface in a classroom setting, providing strong environmental validity to the design process.
\end{abstract}

\section{Keywords}

Curriculum-Focused Design, Cooperative Inquiry, Children, Teachers, Tangible Interfaces, WWW

\section{INTRODUCTION}

Increasingly, HCI researchers are considering the specific needs of sub-populations of users. Children have been recognized as having specific needs [6], and much discussion has taken place on the validity of including their feedback within the design process $[4,14]$. Much of this previous work addresses the needs of children learning in a play setting. While the needs of children receiving structured classroom teaching have been addressed commercially by companies like Leapfrog [9], learning in the classroom has often been neglected in the HCI literature. Therefore we have chosen to focus on supporting the activities of children and their teachers within a structured classroom setting.

Permission to make digital or hard copies of all or part of this work for personal or classroom use is granted without fee provided that copies are not made or distributed for profit or commercial advantage, and that copies bear this notice and the full citation on the first page. To copy otherwise, to republish, to post on servers or to redistribute to lists, requires prior specific permission and/or a fee. IDC2003 7/03 Preston, UK(c) 2003 .ISBN 1-58113-732$X / 03 / 07$..\$5.00
Elliot Soloway challenged the HCI community to move from user-centered design to looking at users who are trying to learn new technologies. Soloway calls this Learner-Centred Design (LCD) [16]. User-Centred Design (UCD) [12] and Learner-Centred Design (LCD) both make technology users central to the design process from the earliest stages of development. These methods focus on empowering users to express their needs, preferences and ideas in ways that can significantly inform the design of the emerging technology.

Our current project aims to develop tangible user interfaces (TUIs) and TUI-controlled applications related to the worldwide web, for use with and by children in the classroom. We began this project with the intention of applying iterative user-centred and learner-centred approaches to the design and development of TUIs. However, we discovered at the trial planning stage that to test our technology in schools, we needed to take account of a range of constraints that we had not initially considered.

The primary issue was the need for our trial sessions to contribute directly and demonstrably to children's learning. Specifically, we had to ensure that the classroom time given to our research would simultaneously enable children to achieve learning goals set forth by the National Curriculum.

There was a range of other constraints introduced by working with children in the classroom during school time. For instance, the timing of trials had to be established well before their content could be planned in detail, there was uncertainty about availability of rooms and equipment in the school, and interruptions from visitors had to be accepted.

The method we evolved to satisfy these constraints, while staying within the spirit of the UCD/LCD approaches, is described in detail below. Our main finding is that there are significant benefits to accepting the constraints of working in schools within the curriculum when the aim is to develop novel technologies to support children's learning in the classroom.

\section{RELATED WORKS}

\section{Learner Centred-Design}

Soloway states [15] that an interface designed according to LCD principles must allow for: 
- Growth - students need to experience a learning environment that is appropriate for their current stage of development, and encourages them to move from there towards a more advanced level of expertise;

- Diversity - the learners in a single class will have a wealth of cultural experiences, and are likely to differ from each other considerably in their cultural backgrounds;

- Motivation - the students' interest in the lesson topic cannot be taken for granted, but should be considered at the stage of lesson design, bearing in mind points (a) and (b) above.

The theoretical underpinning of this approach is constructivism. Constructivism is the basis of current understanding in developmental psychology, and originates in the works of Piaget[13] and Vygotsky[17] respectively. The essential point of constructivism, for the educational process, is that children's minds are not empty vessels passively waiting to be filled up with ready-made knowledge (dispensed by the teacher). Rather, learning and development are active processes, which require the child to engage with his or her environment, including physical objects and tools, peers and teachers. Designing applications which enable children to engage productively with their environment is more difficult for multiple learners and a teacher in a classroom situation than when designing for individual educational play, because of the greater number of variables and constraints involved.

Children's learning environment at school is constrained by and monitored in terms of the objectives specified in the National Curriculum. Thus, for applications designed to support learning in schools, truly Learner-Centred Design requires an understanding of the curriculum.

\section{English National Curriculum}

The National Curriculum applies to all of England's statemaintained schools, as well as to many private schools, if they receive state funding [11]. The National Curriculum determines the content of what will be taught, sets attainment targets for learning, and outlines how performance will be assessed and reported. It attempts to establish equal access and entitlement to education for all children irrespective of social background, culture, race, gender, differences in ability, or disability. The curriculum has three core subjects: English, Maths, and Science, as well as nine non-core foundation subjects (see Figure 1). Student's progress is broken into four key stages. Study is punctuated by mandatory testing at the end of years 2,6 and 9 (i.e. at ages $7+, 11+$ and 14+). Teachers are accountable for every minute of classroom time and must be able to report how each specific requirement was fulfilled.

\section{Our Curriculum Area}

Our research was initially directed by funding that was dedicated to exploring the use of radio-frequency ID-based tangible user interfaces in schools. We carried out a rigorous analysis of the potential advantages of such interfaces over the conventional keyboard and mouse

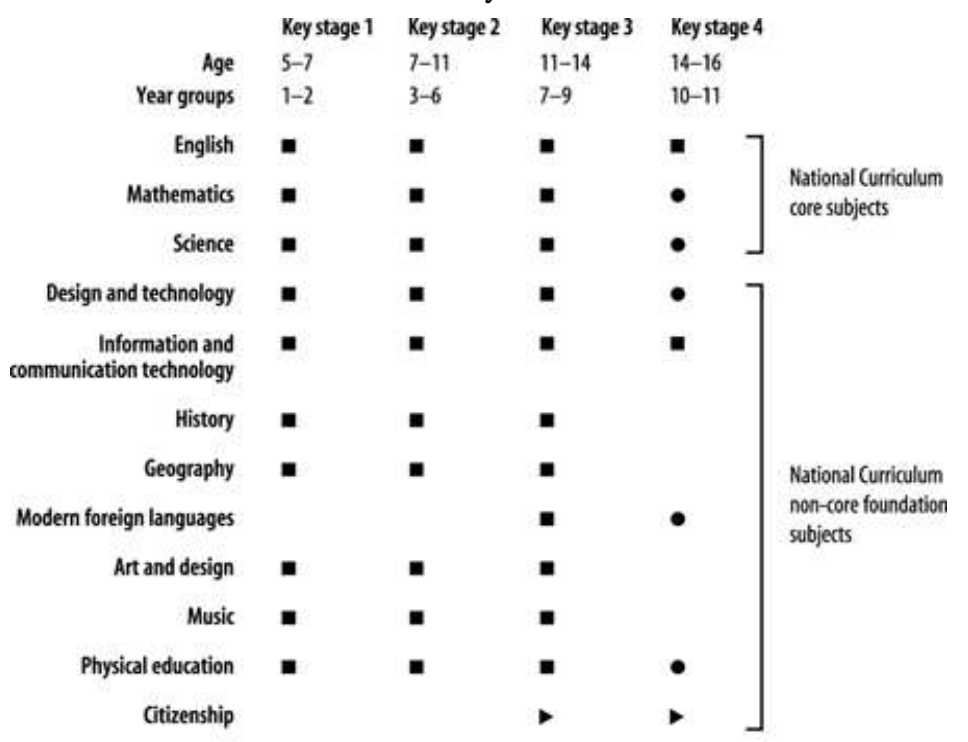

Figure 1. English National Curriculum and subjects taught at the various key stages [11].

interfaces that are normally found in schools [2]. This analysis identified collaborative information use as the activity most likely to benefit from this new technology.

However, the popular emphasis on collaboration in educational HCI research has been criticized by Crook [3]. Crook points out that there is an assumption by many HCI researchers that collaboration is always a good thing; yet from a teaching perspective there is little reason to place such emphasis on collaboration in the classroom. Therefore, rather than assuming that collaboration would necessarily be beneficial for any school activity, we selected an area of the English National Curriculum in which collaboration skills were an explicitly required outcome of the lesson. Working with our partner school and teachers, we agreed to concentrate on argument education. This framework is based on relevant sections of the English, and Citizenship requirements for the appropriate key stages

Students in Key Stage 2 (7-11 years) should learn to [11]:

- Justify what they think based on listening to others (En1 - 'Speaking and Listening')

- Vary their contributions to suit different activities and purposes - tentative comments for exploratory activities, followed by reasoned comments for conclusive activities in En1.

- Identify words associated with reason, persuasion, argument, explanation, instruction and description (En2 - 'Reading', section 5b) 
Key Stage 3 (11- 14 years) Students should learn to

- Use persuasive techniques and rhetorical devices (En3 - 'Writing', section 1j)

- Justify orally and in writing a personal opinion about issues, problems or events (Citizenship, section 2b)

\section{Adapting $\mathrm{HCl}$ Methods to Work with Children}

Traditional HCI methodologies have been adapted to deal with child participants $[1,4,7,8,10$,$] . Allison Druin's$ work has attempted to promote children to the role of active participants in the design process, through the creation of an intergenerational design team. This gives children a much-needed voice in the design process. However, these design sessions do not easily fulfil curriculum requirements; although a case could be made to integrate it into the Design \& Technology track. Our proposal to use this technique within schools was flatly rejected for this reason by our partner teachers, causing us to develop an alternative approach in the class meeting curriculum needs.

A number of authors have discussed potential drawbacks to evaluation during classroom lessons. For instance, Scaife and Rogers discuss the limitations of what children can contribute in classroom settings [14]. They argue that the result of classroom-based design trials is that researchers only gauge children's reactions to a particular interface, but do not get insight into the children's creative ideas about possible alternatives. As a result, researchers and designers take sole responsibility for interpreting the outcomes of design trials, and may miss some important reasons why children liked or disliked the prototypes presented to them.

Druin has raised the concern that because lessons are places where children have little control and carry out adultspecified tasks, researchers will only learn limited amounts under these kinds of conditions [5]. While these and similar objections hold true for design research into unstructured educational play, we would argue that lesson-driven environments are at the heart of our research; therefore a high level of adult control is a natural feature of the environment with which we are concerned, rather than an unrealistic imposition. In addition, while the majority of our sessions have been structured as curriculum-driven lessons, we have reserved a smaller percentage of time for design feedback sessions which are easier for teachers to justify in terms of the curriculum. We have tried to introduce our design feedback sessions in such a way that the children feel comfortable in making critical comments on the lessons and the design prototypes (see Limitations of CFD). Overall, we believe that in adapting HCI techniques to develop technologies for the classroom, there are significant benefits to working within the constraints of the curriculum, because these will be real constraints on the use of the emerging technology.

\section{WEBKIT \& CURRICULUM-FOCUSED DESIGN}

Webkit is a multi-disciplinary project funded by the European Union, comprising of 10 partners both academic and commercial. Its aim is to examine the possible uses of tangible user interfaces and a means of interacting with the world-wide web, with particular focus on the possible use of such applications with schoolchildren. The project is committed to achieving the design and development of new tangible user interfaces (TUI's) and TUI-controlled webrelated applications through a process of user-centred, iterative design.

The project brings together a wide variety of academic research interests in human computer interaction, education and information retrieval, as well as the commercial interests of educational publishing and providers of search engine software.

As project members with responsibility for UI and application design on the project our initial task was to come up with a methodology that would allow us to carry out innovative and iterative user-centred design in a way that would satisfy the interests and concerns of all of the project partners.

Chief among the concerns of our colleague in the educational research field, who benefits from the experience of being a former teacher, was that any trials that we carried out with the schoolchildren should not reduce the amount of the curriculum material covered or cover it in an inferior way.

For our commercial partners, and to fulfil our research brief, it was important that our chosen methodology should result in designs which could easily be deployed in other schools. Our answer to all these competing demands has been to develop a method of user-centred-design which we have called curriculum-focused design. In curriculumfocused design, all the trials that are run in schools are valid as lessons fulfilling part of the National Curriculum as well as being trials of design prototypes. Each trial - or set of trials - is designed in such a way that it demonstrably fulfils a specific requirement set out in the National Curriculum. Each trial must also be designed so that it works within the other constraints of the school environment such technology, accommodation, staffing and timetables.

\section{THE CHALLENGE OF WORKING IN A CLASSROOM}

We found that engaging in design trials within the context of ongoing lessons in a school placed considerable constraints on the ways we were able to test our prototypes. As outlined above, although it was accepted that some of the activities included in the session would be somewhat atypical compared to the children's usual lesson activities, the session had to be planned as a structured lesson in which curriculum-relevant material would be covered. Each session also had to be planned to fit into timeslots of 70 minutes, the length of a lesson at the school where we were working. 


\section{Choosing the Lesson}

We found that those of us on the research team without school-teaching experience could not necessarily easily judge whether activities were either too advanced or alternatively patronizing to the age group of interest (in this case 11-year-olds). The input of our educational specialist was therefore critical in judging the suitability of the proposed activities for the age group concerned, because she had a solid intuitive sense of what level of performance could realistically be expected from 11-year-olds, as well as what sorts of topics would attract and hold their interest. Without her contribution, we would have been much less confident in venturing into the classroom, and our activities and prototypes would have been more likely to fail through simply being inappropriate for the children.

\section{Lesson Stoppers}

Another key concern was making sure the technology did not introduce lessons stoppers. "Lesson stopper" is our term for events or materials that effectively distract children from the curriculum objectives being taught, and in the worst cases, derail lessons completely. Lesson stoppers can be games, animations, or technology that fails in such a way to prevent the main educational objectives to be achieved [18].

\section{Relationship Between Lessons and Iterative Design}

One implication of the need to cover specific curriculum content is that there is little scope for the design trials to deviate from the plan. This is problematic for several reasons. Firstly, prototypes by their nature are liable to break down, and are expected to break down during design trials. Indeed discovering breakdown conditions is one major reason for trialing new technologies with users. Therefore, a type of trial in which prototype breakdown could not be accommodated would be of little use from a design point of view.

Secondly, even if prototypes do not break or fail during trials, the users may not use them as anticipated by the designers. We have called this prototype subversion. Prototype subversion can be done either by children (who often adapt tools in informal ways), or by teachers (who may respond to any perceived weakness in the prototype by modifying the lesson plan on the fly). From a design point of view, this can be very revealing, either because users don't notice, don't understand or are not interested in some features of the prototype, and/or because they discover novel uses or are unexpectedly benefited by other features. However, in the context of a lesson plan, prototype subversion could be difficult for the teacher to accommodate, given the need for specific learning goals to be achieved by the end of the session.

For these reasons, we found that teachers tend to be much more comfortable with testing late prototypes in the classroom, where breakdown is less likely and the possible uses of the technology are already well-defined. Teachers we have encountered have tended not to be either familiar or comfortable with the idea of an iterative design process involving a lot of play, brainstorming, exploring of multiple options and testing of many low-fidelity prototypes. They tend rather to see design as a linear process, in which a single idea is pursued and refined by the designers, and only tested with users at the point where there is little design work left to be done, apart from ironing out a few minor glitches.

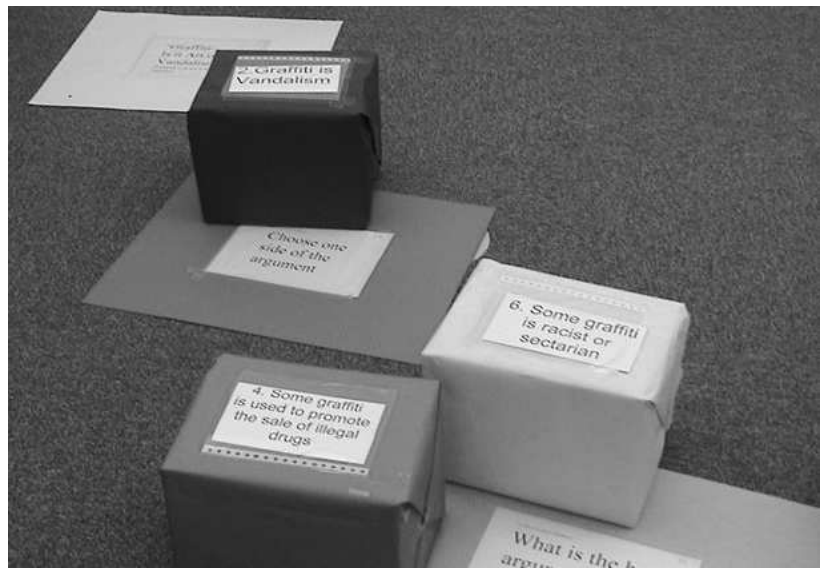

Figure 2. An early low-tech prototype. These kinds of prototypes are generally not recognizable to teachers or children as "technology".

\section{Teachers' Expectations: What is "Technology"?}

A further expectation from teachers which made it difficult for us to pursue an iterative design process was that our prototypes would look like "technology". The idea that paper, highlighter pens, white boards or cardboard boxes (see Figure 2) were "technologies" with interesting affordances was not familiar to them. The children also shared this attitude to some degree, and in early trials, some children expressed disappointment that in a lesson exploring the design of technology they didn't actually see anything that looked like a computer.

In line with this attitude, we found that teachers' expectations of designs for new technology were centred around a desktop PC model. Ubiquitous computing applications, hand-held devices, or other sorts of invisible technologies were outside their existing understanding of possible technology for the classroom. Therefore one of our roles as researcher-designers was to communicate a broader definition of technology to the teachers. This proved a positive tactic for expanding teachers' awareness of the design possibilities and widening the range of suggestions and observations they fed back to us.

\section{The Role of the Prototype in the Classroom}

We explored various ways of working around these difficulties and constraints while maintaining the lessonbased design trial model. We did not wish to be limited to testing only very late prototypes. However we understood the need for a high degree of structure, continuity and predictability about the progress of the lesson. We therefore adopted an approach and specific tactics to enable the trials 
to continue productively for the design process, while at the same time satisfying the demands of the curriculum.

Essentially, we aimed to design lesson plans that were robust in the face of prototype failure. In other words, we accepted that the prototype might break down completely, or turn out not to be useful in the expected ways, but we had to design the lessons such that prototype failure or subversion did not stop the lesson.

\section{The Prototypes}

The requirements and constraints on performance and educational value outlined above led us to design initial trials which might be characterised as "no-tech" - using print-outs of web pages relevant to the topic of discussion. Our aim here was to understand thoroughly the process that we were trying to augment under conditions in which no novel technology was yet involved. This caused some surprise amongst our teaching colleagues, who had been expecting a "technological" prototype. It also caused some disappointment amongst our schoolchildren participants who had been anticipating the opportunity to try out some new gadgets.

We then introduced a series of "low-tech" trials with a new group of children, in which prototypes were introduced which did not involve any electronic information technology. The aim of these prototypes was to augment and facilitate the process which we had seen in the "notech" paper trials. We tried to design these augmentations in such a way that if they did not help at all, they would still not interfere too much with the progress of the lesson and its value to the children.

In our third series of trials we moved away from the entirely paper-based lesson structure that had been the basis of previous trials and introduced a "low-tech" prototype which was central to the conduct of the lesson. This was done in close consultation with our teacher colleagues as to educational suitability and viability. Because there was no contingency plan for the possibility that this prototype might fail to work, we first carried out pre-trial pilot trials with naïve young adults, with the aim of ironing out any obvious functionality problems (see Pilot Trials). We then ran a series of trial lessons with children.

Finally, in our fourth series of trials, we began to augment the "low-tech" prototype used in the previous set of trials with graphical and audio feedback, triggered using RF-ID tag technologies. Again these introductions have been done in such a way that the lesson can still proceed and be valuable to the children, even if all the electronic augmentation fails.

While such a gentle and incremental approach to the introduction and trialling of technology is in many ways very limiting, it does also have profound benefits. The focus of design effort is on the learning goals of the children and on the learning materials that they need to use to achieve them.

\section{Pilot Trials}

In order to check that the lesson plans and the prototypes could function at least minimally as we intended, we ran mock-ups of the activities before running them in schools. For these "dummy" trials, we initially tried out the activities and prototypes ourselves as a research team. Then we ran dummy trials with naïve older adolescents and young adults. Naturally we were aware that running trials with ourselves or with adolescents or young adults was not a test of whether the activities could be expected to work with 11-year-old children. However, we realized that if the activities we envisaged or the prototypes we had made broke down when we tried them out ourselves, there was no hope that they would be useful with children. So this part of the process enabled us weed out some very basic functionality issues with prototypes before we took them into the classroom. It also gave us scope to experiment with more very early prototypes than we could realistically test in the classroom under lesson conditions. Finally it allowed us to ensure that lesson activities were viable even in the face of prototype breakdown. In practice, neutralizing the problem of prototype breakdown in this way meant that prototype subversion was still possible (as we wanted it to be, to inform the design process), but when it happened it was unlikely to subvert the lesson plan at the same time.

\section{The Lesson/Design Trial Session}

The lesson/design trial session is itself a novel experience that bears resemblance to a Think Aloud session and ethnography carried out in tandem. Our lessons were given to small groups of five or six children (all drawn from the same class) by a member of our research team who is a teacher and educational specialist. This relieved the regular teacher to work more closely with the remaining students. Both taught a similar topic, one with and one without technology. This required considerable coordination between these two teachers. We envisage that at later stages of the design process, the lesson could be given by the regular teacher to the entire class, once the prototype is robust enough to work as a full class activity.

Part of a teacher's normal role in the classroom is to elicit feedback from pupils to determine how they are getting on with tasks. We have found that the information elicited by our education specialist in her role as "teacher" to the small group is very similar to that gathered when an evaluator probes a participant in a think aloud protocol in more traditional HCI studies. Our education specialist is not directly involved in the design of the TUI, although she has provided valuable feedback on the prototype TUIs from an educational perspective; this has included choosing and researching suitable lesson topics for use with the prototypes in the design trial lessons. We consider that the TUI and the related lesson plans are equally important outcomes of the design process. Other researchers, who were directly engaged in the design process, have been observing the sessions in an ethnographic fashion, as if they were observing normal lessons. Children have been invited to give feedback in 
two ways: written questionnaires, and verbal feedback sessions. The written questionnaires allow children to express their individual opinions without feeling social pressure to conform to the group opinion. This is followed with a critique session as students may be more comfortable expressing themselves verbally than in writing. Additionally we have found that the children often engage in debate with each other and the teacher, and are inspired by each others' feedback. Following the session, the children's opinions, the education specialist's opinion of how well the lesson objectives were achieved, and the other researchers' observations of the children's reaction to the interface can be used to feed back into the next iteration of the design.

\section{Other Constraints of Working in a Classroom}

This approach has worked well for us, and has enabled us to get fruitful design output from trials run as curriculumbased lessons. In pursuing the research, we have also had to take into account a number of other issues. None of these are as critical as those considered immediately above, in terms of potential to derail the design process as a whole. However, all of them need to be taken into account when doing this kind of research in schools.

\section{Subject to scrutiny; from above and below}

We have already discussed the need for the design trial lessons to meet the same curriculum-satisfying criteria as other school lessons. In addition, schools are constantly subject to scrutiny from a variety of visitors, any of whom may decide to visit a design trial lesson while it is in progress. Such visitors could include school inspectors (who planned to visit one of our lessons, but then changed their plans), politicians (the local Member of Parliament interrupted one of our lessons and interviewed the children participating about what they were doing) or parents. Clearly anything happening in the classroom has to be acceptable to any of these potential visitors. Perhaps less obviously (but equally importantly), it is not possible to refuse to allow interruptions from such visitors because of the effect on the research. The normal business of the school inevitably has to take precedence.

As previously mentioned, the area of the curriculum with which our activities are concerned is about argument and discussion, and therefore it is necessary to design lessons based around topics about which there is some degree of controversy. Indeed the curriculum demands that children deal with "difficult" issues when developing their discussion and argument skills. At the same time, however, there are some topics which are highly politically sensitive, and which it would be unwise and inappropriate to use as the basis for a classroom discussion. As a research team, we found ourselves dependent on the experience of our colleague with teaching experience for the selection of suitable discussion topics. This was because she had longstanding experience of working in a classroom environment, and was aware of the sorts of topics that would be acceptable in the classroom and those that would not. While not all educational technology research faces this particular problem, it is a good example of the need for input from an experienced teacher.

\section{The environment: moving from the lab to the classroom}

Running design trial lessons in a school does mean that researchers' control over the physical environment and resources available for trials is rather limited. It is usually impossible to guarantee that the lesson will take place in a room of the desired size, the immediate environment may be noisy, and promised equipment may turn out to be unavailable at the last minute. As far as possible, it is wise to be prepared for all contingencies. Set-up time is also likely to be quite limited because it the room may be in use for another lesson immediately before the trial lesson.

\section{Advanced planning required}

Considerable forward planning is required from a purely administrative point of view. Researchers planning to work with children may be asked by the school to obtain police clearance beforehand. This generally takes several weeks. When planning specific lessons, we have found that we usually have to commit to particular dates before we know what we will be doing, or indeed whether we will have anything ready to try out. This is because many teachers plan their lessons quite far ahead, and they need to know whether they need to work around the research plans. Once dates have been agreed, they cannot be changed without causing considerable inconvenience to the teachers and risking damaging professional relationships. This places the design process under strains that make no positive contribution to the output, but have to be tolerated for the sake of respecting the smooth running of the school and maintaining goodwill in our research relationship with them.

\section{Participant selection}

As researchers, we have limited control over the selection of the children in the group. On the whole, this is a good thing, as we want to try out our designs in real classrooms, with a group of children who are used to being in the same class on a daily basis. 11-year-olds in England are mostly taught in mixed ability classes (apart from English and Maths lessons). Thus, by testing the technology with mixed ability groups, we are in a position to find out how flexible it is in typical classroom situation. Our methodology has not been designed to investigate whether the technology would be particularly suited to supporting learning for children in specific ability ranges, although future work could address this.

\section{Research Benefits of Working within a School}

In spite of the constraints and difficulties outlined above, we see a number of advantages to the Curriculum-Focused Design approach. Firstly, once a relationship with a school has been established, recruiting children to participate in the research is relatively straightforward, as the research is part of an activity for a whole class, rather than something for which certain children have to be selected. Since the research itself integrates material from the curriculum, it can take place during normal lesson time, rather than after 
school hours or during lunchtimes. This significantly increases the number of research sessions with children that can be achieved within a limited period.

Besides these purely practical benefits, the fact that the research is being conducted with a real class of children has helped our design process in several ways. The social relationships between the children are genuine. Therefore, the collaboration seen between children the in the design trial lessons is likely to reflect real patterns of collaboration usually seen in their class, rather than collaboration between children who have never interacted with each other before.

In addition, by taking on board all the constraints of the school environment at the design stage, we believe we are achieving more realistic feedback on the conditions under which the technology we design will actually have to perform. In summary, these are:

- in a curriculum-focused context

- in the classroom environment

- within the administrative and regulatory framework of the school

- without introducing lesson stoppers created by the design

These constraints are not necessarily relevant to designing technology for children to use outside educational contexts, but when the technology concerned is intended to integrate with the curriculum, they are extremely important and need to be taken into account in the design process.

\section{Limitations of CFD}

Curriculum-focused design is a useful method, but limited in its scope in various ways. Firstly, since we have yoked our research to the English National Curriculum, we cannot guarantee the applicability of our technology outside English classrooms. We also accept that as our work has been done in a single school, there may be design-relevant respects in which that particular school is atypical. More extensive user testing and development in other schools could help to make the resulting technology more robust and flexible in a range of educational contexts.

Secondly, while we have deliberately designed our trials to cope in the face of technology breakdown, we have been working with relatively low-technology prototypes so far. Fragile high technology prototypes might cause difficulty for this kind of design method; there could be greater scope for the teacher getting sidelined into trying to "fix" broken technology, and the lesson could get derailed as a result.

Finally, evaluation of technology in the classroom, particularly when it is being used collaboratively, is qualitative and observational rather than quantitative. Formal quantitative evaluation of the children's educational performance with and without technology support, might be relevant to the strongly assessment-oriented nature of the National Curriculum in a later study. To date we have found that our simple and deliberately 'child-friendly' questionnaires about the design lessons have generated useful data about the children's experience of the design trial lessons. We are also considering using discourse analysis to look at the content of the children's conversations during the lessons.

One evaluation issue we have been concerned about is that in completing questionnaires or giving verbal feedback, children may be reluctant to offer criticism of a lesson to the teacher who conducted it. However this can be dealt with effectively by using another member of the research team to conduct the evaluation session and collect the questionnaires from the children. In addition, when introducing the feedback sessions and questionnaires, we have stressed that criticism is helpful to us. In practice, we have not had difficulty in eliciting negative as well as positive comments from the children.

\section{CONCLUSION}

Curriculum-Focused Design is not the easiest way of doing User Centred Design. By deciding to conduct research with in the framework of the school's physical, regulatory and educational structures, we have given up a lot of the creative control that we cherish as design researchers whilst at the same time acknowledging a large number of additional constraints.

Such an approach doubtless has drawbacks. Focusing on the school curriculum inevitably restricts the ability of the researchers to involve children creatively. On the other hand, teachers have been more significantly involved in a process that requires that their professional concerns are explicitly acknowledged and addressed. In our method, early prototypes need to be more robust than would be necessary for Druin's Cooperative Inquiry approach, so that the prototypes can confidently be introduced into a lesson which must deliver educational value in curricular terms. Yet this too has had its positive effects, as outlined above; for instance, it has forced us to get the physical affordances of the interface right before we introduced any unavoidably buggy electronic technology.

The major benefit of focusing on the curriculum in tandem with pursuing the design process is that we have revealed many environmental constraints on the introduction of new technology into schools. We claim that our awareness of these constraints of space, time, equipment, regulation and education has led us to design applications with strong environmental validity. This should make them easier to introduce into schools, easier to use by schoolchildren and teachers, and more likely to be used by teachers who are always conscious of their curricular obligations. Furthermore, the addition of design constraints that lie outside the usual technical factors has provided a creative impetus for our research.

Curriculum-Focused Design is a method motivated by the same principles of growth, diversity and motivation which inform Learner Centred Design, and as such is a specific application of the LCD approach. We believe that Curriculum-Focused Design is a viable and valuable 
approach to the design of interfaces and applications which are to be used by schoolchildren in the classroom.

\section{ACKNOWLEDGMENTS}

We would like to thank the year 7 students and the teachers in the English and ICT departments at Trinity School in Leamington Spa. This research is funded by the European Union, grant no. IST-2001-34171. (Please note that the authors are solely responsible for the content of this publication and it does not represent the opinion of the European Community. The European Community is not responsible for any use that might be made of data appearing within this publication.)

\section{REFERENCES}

1. Bekker, M., J. Beusmans, D. Keyson and P. Lloyd. KidReporter: a method for engaging children in making a newspaper to gather user requirements. Interaction Design \& Children. (2002), 138-43.

2. Blackwell, Alan. Cognitive Dimensions of Tangible Programming Languages. Proceedings of the first joint conference of the Empirical Assessment in Software Engineering and Psychology of Programming Interest Groups (2003), 391-405.

3. Crook, Charles. Children as Computer Users. Computer Education. 30, 3/4 (1988). 237-47.

4. Druin, Allison. Cooperative inquiry: developing new technologies for children with children. Conference proceedings on Human factors in computing systems. (CHI 1999), 592-9.

5. Druin, Allison. Children as Our Technology Design Partners. The Design of Children's Technology. (1999), 51-72.

6. Druin, Alison. A Place Called Childhood. Interactions. 3,1 (1996).

7. Hanna, L., Kirsten Risden, Mary Czerwinski and Kirstin J. Alexander. The Role Of Usability Research In
Designing Children's Computer Products. The Design of Children's Technology. (1999), 3-26.

8. Höysniemi, J., P. Hämäläinen, and L. Turkki. Using peer tutoring in evaluating the usability of a physically interative computer. Interaction Design \& Children. (2002), 144-52.

9. Leapfrog

Available at http://www.leapfrogschoolhouse.com/research/index.asp

10. Markopoulos, P. and M. Bekker. How to compare usability testing methods with children participants. Interaction Design \& Children. (2002), 153-8.

11. National Curriculum. Available at http://www.nc.uk.net/home.html.

12. Norman, D. and S. Draper. User Centered System Design. L. Erlbaum \& Associates, Hillsdale, NJ (1986).

13. Piaget, J. The Construction of Reality in the Child. Basic Books, New York. (1954).

14. Scaife, M. and Y. Rogers. Kids As Informants: Telling Us What We Didn't Know Or Confirming What We Allready Know. The Design of Children's Technology. (1999), 27-51.

15. Soloway, Elliot, Nancy Scala, Shari L. Jackson, Jonathan Klein, Chris Quintana, James Reed, Jeff Spitulnik, Steven J. Stratford, Scott Studer and Jim Eng. Learning theory in practice: case studies of learnercentered design. Conference proceedings on Human factors in computing systems. (CHI 1996), 189-96.

16. Soloway, Elliot, Mark Guzdial and Kenneth E. Hay. Learner-Centered Design: The Challenge for HCI in the 21st Century. Interactions. 1,2 (1994), 36-48.

17.Vygotsky, L.S. Thought and Language. MIT Press, Cambridge, MA.. (1962).

18. Wood, Julie. Ten Ways to Take Charge of the Web. http://teacher.scholastic.com/professional/teachtech/ten ways.htm 